\title{
La orientación profesional en la Argentina (1920-1955): un ejercicio de historia del presente
}

\section{Victoria Haidar*}

Resumen: Este artículo examina las procedencias, múltiples y heterogéneas, de la orientación profesional en la Argentina, con la finalidad de mostrar que su configuración en el presente es, en parte, singular y, en parte constituye una reformulación de temas de más larga data. A partir del análisis de un corpus integrado por discursos históricos (1920-1955) y otros de actualidad (1999-2012), provenientes del campo de los saberes expertos y la política pública se observan las continuidades y discontinuidades que caracterizan su problematización: la limitación de sus propósitos, la persistencia del "tema" de la empleabilidad, el desplazamiento entre un énfasis inicial en la satisfacción de fines sociales y la actual importancia atribuida a la realización personal y su continuo funcionamiento como una estrategia "transaccional", que procura el ajuste entre los deseos individuales y los requerimientos del mercado.

Palabras claves: orientación profesional, empleabilidad, productividad.

\begin{abstract}
This article examines the multiple and heterogeneous sources of professional guidance in Argentina, in order to show that its configuration in the present is partly unique and partly constitutes a reformulation of longer-standing issues. Through the analysis of a corpus comprising historical (1920-1955) and current discourses (1999-2012), belonging to the field of expertise and policy, we observe the continuities and discontinuities that characterizes its problematization: the limitation of its purposes, the persistence of the "theme" of employability, the displacement between an initial emphasis on meeting social goals to the current emphasis on personal fulfillment and its continued operation as an "compromise" strategy which seeks the fit between individual desires and market requirements.
\end{abstract}

Keywords: professional guidance, employability, productivity.

\section{Introducción}

En la actualidad argentina, la orientación profesional designa un campo específico de estudios e intervenciones con su correspondiente repertorio de instituciones, revistas especializadas y textos fundadores. Inscripta en el ámbito más general

* Consejo Nacional de Investigaciones Científicas y Técnicas. Universidad Nacional del Litoral (Argentina).vhaidar@fcjs.unl.edu.ar 
de la(s) psicología(s), pero en diálogo constante con las ciencias de la educación, la misma reconoce, en ese país, una historia cuyos orígenes se remontan a la década del '20 del siglo XX. Su desarrollo en el campo laboral y educativo es, incluso, muy anterior a la profesionalización de la psicología, ocurrida recién hacia mediados de los años '50'. En esa dirección, las iniciativas de los psicólogos, médicos, filósofos, educadores etc. en el terreno de la psicotécnica² son recuperadas por los historiadores como uno de los antecedentes más firmes del enraizamiento de dicha disciplina en el país. La misma comenzó a ser practicada por los socialistas, que promovieron la utilización de la fisiología y la psicología experimental para la resolución de los diversos problemas que planteaba el trabajo industrial. ${ }^{3}$

Un segundo núcleo de experiencias, inscriptas en el campo de la psicología experimental y afines a las ideas krausistas ${ }^{4}$, fue impulsado por el filósofo y psicólogo alemán Carlos Jesinghaus, discípulo de W. Wundt, quién en el seno del "Congreso del Trabajo" realizado en el año 1923 en la Provincia de Santa Fe, propuso la creación de un "Instituto Central de Orientación Profesional”. Dicho proyecto, que contaba con el respaldo de Antonio Sagarna, el Ministro de Justicia e Instrucción de la Nación, se concretó durante el gobierno del presidente radical Marcelo T. de Alvear. Instalado en 1925 en la ciudad de Buenos Aires, el Instituto de Psicotécnica y Orientación Profesional atendía consultas, realizaba exámenes médicos y psicotécnicos, publicaba como material ad hoc una "Guía de Estudios Superiores" y una "Cartilla de Orientación Profesional". Además, funcionaba como un centro de formación de orientadores. Entre sus responsables, además de su creador, estaba el psicólogo Gregorio Fingermann, quién se ocupó de continuar con la tradición del estudio integral de la personalidad iniciada por Jesinghaus en la Argentina, cuando este último regresó a Alemania.

Con el golpe de Estado que, en 1930, encabezó el general José F. Uriburu y que puso fin al gobierno del presidente radical Hipólito Irigoyen, el Instituto fue desfinanciado. En 1931, el Museo Social Argentino (una institución creada en 1911 sobre el modelo francés) solicitó al Ministerio de Justicia e Instrucción Pública la donación del material del laboratorio para crear y sostener el Instituto como uno de sus organismos. Bajo la dirección de Fingermann, el mismo prestó servicios de orientación y selección tanto a instituciones de las fuerzas armadas como a establecimientos privados e inspiró la creación de gabinetes psicotécnicos en otras ciudades.

Durante la década del '3o la orientación profesional concitó el interés del movimiento biotipológico ${ }^{5}$ desarrollado en la Argentina al calor de las ideas de Nicola

1 KLAPPENBACH, Hugo y PAVESI, Pablo. “Una historia de la psicología en Latinoamérica”. Revista Latinoamericana de Psicología, Bogotá, v. 26, n. 3, p. 445-481, 1994.

2 La psicotécnica es el término que se utiliza desde los primeros años del siglo XX para designar el estudio analítico de las diversas aptitudes que el hombre emplea en cualquier forma de actividad. Definida por primera vez por William Stern en 1903, el concepto recién fue puesto en circulación por el psicólogo alemán Hugo Münsterberg hacia 1911.

3 ROSSI, Lucía. "Los socialistas y la psicología: tres momentos en el marco de la cátedra de psicología fisiológica y experimental en la Universidad de Buenos Aires”. En ROSSI, L. y colaboradores. Psicología: su inscripción como profesión. Buenos Aires: Eudeba, 2001, p. 101-112. Si bien relevantes, a lo largo del artículo no volveremos sobre estos antecedentes porque los mismos no incluyen referencias a la orientación profesional.

4 El krausismo es una filosofía espiritualista que emergió a comienzos del siglo XIX en oposición al positivismo materialista, y cuyo creador fue el filósofo alemán Karl C.F. Krause (1781-1832). En Argentina, dicha corriente tuvo incidencia sobre el pensamiento y las prácticas del partido radical, particularmente sobre el ex presidente Hipólito Irigoyen. Sobre la incidencia de esta filosofía en dicho país vid. BIAGINI, Hugo (comp.). Orígenes de la democracia argentina. El trasfondo krausista. Buenos Aires: Legasa, 1989.

5 La biotipología es una corriente fundada en Italia en la primera posguerra por Nicola Pende que se pensó como la instrumentación práctica de la eugenesia en el mundo latino. En la Argentina, el clima propicio para su difusión llegó con el golpe de Estado de 1930, por la simpatía que despertaba en su líder castrense las ideas del fascismo italiano 
Pende y Agostino Gemelli. Ya la Asociación de Biotipología, Eugenesia y Medicina Social, creada en 1932, contaba con una Oficina de Psicotécnica y Orientación Profesional. Para los adeptos a esa corriente (como los médicos Arturo Rossi y Donato Boccia), no era posible hacer psicotécnica sin la base de la biotipología porque mientras ésta estudiaba la totalidad del individuo, aquella era sólo una parte especializada de la misma.

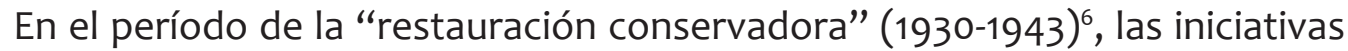
en el campo de la orientación profesional provinieron de la sociedad civil. Pero hacia mediados de los años' 40, de la mano del proceso de industrialización sustitutiva de las importaciones, la psicotecnia volvió a ser impulsada, como en los '20, por el Estado. En 1944, la conducción militar que se impuso luego del derrocamiento del presidente conservador Ramón Castillo (y que gobernó entre 1943 y 1946) estableció la Dirección Nacional de Aprendizaje y Orientación Profesional, cuya labor se concentró, sobre todo, en orientar a los jóvenes aprendices de oficios industriales.

Durante los dos gobiernos del general Juan D. Perón (1946-1952, 1953-1955) la cuestión de la orientación profesional recibió un gran impulso en el contexto, más general, de su política de fortalecimiento y expansión de la enseñanza técnica, institucionalizándosela a través de dos vías privilegiadas: la inclusión en el texto de la Constitución reformada de 1949 y su consideración como uno de los "instrumentos” del Segundo Plan Quinquenal, el programa económico-social del peronismo.?

Todas estas iniciativas y reflexiones que tuvieron lugar en Argentina se inscribían en el marco de un contexto internacional y latinoamericano que impulsaba el desarrollo de la psicotécnica. Así, la primera Conferencia Internacional de Psicotécnica se realizó en Ginebra en el año 1920, repitiéndose a lo largo de los años. Ya en 1928 la OIT había señalado la importancia que la misma tenía para la industria. También en otros países de Latinoamérica el período de entreguerras estuvo caracterizado por la organización de diferentes dispositivos de orientación profesional, así como por su reconocimiento en el campo jurídico. Merece destacarse el caso de Brasil, cuya Constitución Federal de 1937 y, posteriormente, las Leyes Orgánicas de 1942, 1943 y 1946 contemplaron esta institución. El despliegue de la psicotécnica estuvo muy influenciado, en dicho país, por la acción de Emilio Mira y López, un psicólogo cubano, radicado en España y exiliado de la dictadura franquista en Argentina, que residió varios años en Brasil. En 1947, se organizó, bajo la dirección de dicho especialista, el Instituto Nacional de Selección y Orientación Profesional de Brasil, aunque ya en 1931 se había instaurado un servicio estatal de Orientación Profesional en el estado de Sao Paulo. ${ }^{8}$

En lo que refiere al caso argentino, del que nos ocupamos aquí, entre 1920 y 1955 la orientación profesional fue problematizada en direcciones múltiples e incluso contradictorias. Algunos de los temas que emergieron en el marco de esas reflexiones han despertado la atención de los historiadores de la psicología, quienes

6 ROMERO, Luis. Breve historia contemporánea de la Argentina. Buenos Aires: Fondo de Cultura Económica, 2001.

7 El artículo 37 de la Constitución de 1949 prescribía que "la orientación profesional de los jóvenes (...) es una función social que el Estado ampara y fomenta mediante instituciones que guíen a los jóvenes hacia las actividades para las que posean naturales aptitudes y capacidad, con el fin de que la adecuada elección profesional redunde en beneficio suyo y de la sociedad". Por su parte, el Segundo Plan Quinquenal establecía que una de las bases sobre las que debía organizarse la política social y laboral era el "establecimiento de correlaciones racionales entre la aptitud del trabajador y su ocupación, a fin de obtener los más altos índices de productividad y de retribución." KLAPPEBACH, Hugo. "Historia de la orientación profesional en Argentina". Orientación y Sociedad, La Plata, n. 5, p. 1-14.

8 GONZÁLEZ BELLO, Julio. "La orientación profesional en América Latina. Fortaleza, Debilidades, Amenazas y Oportunidades”. REMO, México, v. 5, n. 13, p. 44-49, nov. 2007-feb. 2008. 
se han ocupado, particularmente, de trazar periodizaciones. ${ }^{9}$ Teniendo en cuenta esos antecedentes, pero sin ser fieles a las compartimentaciones que proponen, el propósito que perseguimos en este artículo consiste en exhibir las procedencias, a la vez múltiples y heterogéneos, de la orientación profesional en dicho país, con la finalidad de explicitar tanto el carácter singular (novedoso, inédito) de su presente como las "memorias discursivas" que resuenan en él, participando en la construcción de su sentido.

Ciertamente, la pregunta por las formas, cambiantes, en que dicha cuestión se ha problematizado tiene muchas aristas. En el marco de esta contribución nos centraremos sobre dos de ellas: la pluralidad de objetivos a los que respondió y el peculiar esfuerzo de articulación entre una dimensión o plano "macro" de acción y otra dimensión o plano "micro" sobre la que se funda. ${ }^{10}$

Así, en la sección II mostraremos que, contra la actual tendencia a reducir la orientación profesional a una estrategia dedicada a mejorar la empleabilidad de diversas poblaciones (sub-sección II.1), la misma ha sido utilizada, a lo largo de la historia, para múltiples propósitos, que incluían la cuestión de las condiciones para el empleo y la productividad de la fuerza de trabajo (sub-sección II.2), la lucha contra el desempleo (sub-sección II.3), la prevención de los accidentes de trabajo (sub-sección II.4) y la pacificación social, objetivo este último que, por razones expositivas será objeto de consideración en la sub-sección III.2. Una vez explicitada la naturaleza polivalente de la orientación profesional, nos ocuparemos del análisis de los diversos planos o niveles sobre los que la misma opera - un plano macro o "social", y otro micro o "ético" -; así como de las relaciones que se establecen entre esos diversos niveles de operatividad, los saberes expertos sobre los que esa práctica se funda y las racionalidades que, en distintos períodos de la historia argentina, han inspirado el "gobierno" "1e las poblaciones. Así en la sub-sección III.1. sostendremos que, en la actualidad, la orientación profesional responde a

9 Desde la historia de la psicología se vinculan las transformaciones tanto de las prácticas de orientación y selección profesionales como de los dispositivos de inscripción utilizados en el curso de las mismas con dos grandes procesos de carácter socio-político: la democratización y la individualización de la sociedad. Lucía ROSSI (Abordaje genealógico de protocolos según géneros y áreas profesionales. Sujeto implícito. Ponencia presentada en el II Congreso Internacional de Investigación y Práctica Profesional en Psicología, Buenos Aires, 2010) encuentra una correspondencia entre el uso de dispositivos que permitían representar a los sujetos en tanto individualidades biográficas y los períodos de "democracia con participación ampliada" (década del '20 y 1946-1955) y entre el empleo de fichas que tornan irrepresentable la singularidad y el régimen de "democracia con participación restringida" (1930-1946). H KLAPPENBACH ("Historia de la orientación...", op. cit.) distingue dos etapas: una etapa de la orientación profesional colectiva, coincidente con la implementación de políticas “planificadoras" (hasta fines de los' 50) y una segunda etapa de orientación individual que coincide con el ocaso de las ideologías planificadoras y el giro "clínico" que se le imprimió desde los' 70.

10 Así, a lo largo del artículo nos concentraremos en analizar de qué manera esas dos cuestiones (en el sentido de "temas" y de "formas de interrogación") se hicieron pensables en toda una serie de discursos. Eso involucra, de por sí, la desconsideración de otras preguntas relevantes, tales como aquellas referidas a la realización de acciones de orientación profesional, su impacto sobre las poblaciones, el logro de los objetivos que se perseguían con ellas etc. Más allá de ello, en diferentes momentos del texto haremos algunas referencias (en función de los datos disponibles) a esas dimensiones atinentes a la "efectuación", en las prácticas, de la orientación profesional, con la finalidad de incorporar a la reflexión elementos que permitan ponderar la relevancia que los expertos, entre otras autoridades, le atribuían.

11 Por "gobierno" nos referimos a lo largo de este artículo a una forma específica de ejercer el poder, entendido en términos de conducción de conductas. En este sentido, el gobierno no se refiere solamente a la dirección política del Estado, sino que designa una actividad práctica más o menos calculada y racional, llevada a cabo empleando una variedad de técnicas y formas de conocimiento, que procura modelar la conducta (de uno mismo, de un individuo, grupo o población) operando sobre los deseos, aspiraciones, intereses y creencias de los sujetos (cf. FOUCAULT, Michel. "Porqué estudiar el poder. La cuestión del sujeto”. En: DREYFUS, Hubert y RABINOW, Paul. Michel Foucault: más allá del estructuralismo y la hermenéutica. Buenos Aires: Nueva Visión, 2001, p. 241-259 y DEAN, Mitchell. Governmentality. Power and Rule in Modern Society. London: Sage, 1999). 
las demandas de los "individuos" y activa procesos de formación de identidades centrados sobre las ideas de "elección”, "auto-construcción” y "responsabilidad personal". Asimismo, argumentaremos que ello se debe a la convergencia entre el giro "clínico" psicoanalítico que se le imprimió en la década del '70 y la incidencia que el neoliberalismo ejerce sobre la política laboral y social argentina desde la década del '90. Por el contrario, en la sub-sección III.2. explicaremos que, entre 1920 y 1955, la orientación fue problematizada desde un punto de vista colectivo, articulándose con una serie de racionalidades y discursos políticos y éticos de carácter "social" y "nacionalista" o que, al menos, insistían en torno a la integración entre los intereses "individuales" y aquellos "colectivos". Matizando esas afirmaciones, no obstante, en la sub-sección III.3. defenderemos la idea de que, en todos los casos, el funcionamiento de la orientación profesional como una "tecnología de gobierno" 12 , se asienta sobre un delicado juego de "ajustes" entre el plano "micro" del individuo y "macro" de la sociedad. Finalmente, plantearemos una serie de conclusiones (sección IV).

Desde un punto de vista teórico-metodológico, este artículo se inscribe en una línea de indagación que combina herramientas provenientes de la historia del presente ${ }^{13}$, la sociología de los saberes expertos y la teoría materialista del discurso. Su propósito es mostrar cómo lo que en el presente se dice (y por lo tanto, se piensa) acerca de la orientación profesional, está condicionado, en parte, por discursos de más largo alcance y cómo, en parte, es novedoso. Para ello, se analiza un corpus que pone en diálogo dos series discursivas, que permiten que el análisis se efectúe en un doble registro sincrónico y diacrónico. Por un lado, un "dominio discursivo de referencia" 14 integrado por enunciados provenientes del campo científico y del campo de la política social. Concretamente, las formulaciones analizadas se tomaron de artículos publicados por expertos argentinos en revistas especializadas entre 1999-2012, período que coincide con la creación de la revista argentina Orientación y Sociedad y que llega hasta la actualidad. Asimismo, como expresión del discurso de la política social se incluyó un "Manual de Formación" en orientación profesional elaborado en el año 2006 en el marco del Programa de Calidad del Empleo y la Formación Profesional del Ministerio de Trabajo, Empleo y Seguridad Social de la Nación (en adelante MTEySS). ${ }^{15}$ Por otro lado, un "dominio discursivo de memoria" 16 constituido por enunciados procedentes, asimismo, tanto del

12 Por "tecnología de gobierno" entendemos aquí una regularidad que organiza las acciones de los individuos según cierto conocimiento, orientándolas hacia un fin. De lo que se trata, en el caso de la orientación profesional como de muchas otras tecnologías de gobierno, es de modelar la conducta con la finalidad de aumentar y optimizar las capacidades, las aptitudes o el estado de los individuos.

13 La "historia del presente" es un enfoque emplazado entre la historia de las ideas políticas y la sociología de las tecnologías de gobierno que ha sido desarrollado por un conjunto de investigadores de habla inglesa, a partir de la recuperación de los conceptos foucaultianos de "gobierno" y "gubernamentalidad". En tal clase de análisis, el presente se aborda como un "conjunto de cuestiones". Su finalidad es revelar la pluralidad de piezas de procedencias diversas que lo componen, la nuda contingencia y la historicidad de lo que parece coherente, natural y contemporáneo (cf. BARRY, Andrew; OSBORNE, Thomas \& ROSE, Nikolas. "Introduction”. En: BARRY, A.; OSBORNE, T. y ROSE, N. Foucault and Political Reason. England: UCL Press, 1996).

14 El dominio de referencia (COURTINE, Jean-Jacques. “Análisis del discurso político". Langages, n. 62, p. $1-100,1981$.) incluye los textos que delimitan el corpus y funcionan como centro orientador del análisis. En este caso está conformado por enunciados que, entre 1999 y 2012, tematizan la orientación profesional, tanto en el campo de la política social como académico.

15 El Programa de Calidad del Empleo y de Formación Profesional fue creado en el año 2004 por la Secretaría de Empleo del MTEySS en el ámbito de la Dirección Nacional de Orientación y Formación Profesional. Su finalidad consiste en implementar mecanismos de asistencia técnica a una serie poblaciones formadas por individuos ocupados y desocupados, con la finalidad de incrementar su empleabilidad.

16 El dominio de memoria (COURTINE, Jean-Jacques "El discurso..." op. cit.) se delimita a partir de series discursivas que conforman las capas de la memoria (citadas, retomadas, contestadas, eludidas, olvidadas o denegadas) de los documentos del campo de referencia. 
campo científico (artículos publicados en revistas especializadas, libros) como del campo político (planes de gobierno, leyes), aparecidos entre 1920 y $1955 .{ }^{17}$ Dicho período se inicia con las primeras reflexiones sobre la orientación profesional que se registran en el país y culmina con el golpe de Estado que puso fin al segundo gobierno peronista.

\section{La orientación profesional: una tecnología polivalente}

La problematización actual de la orientación profesional se desarrolla en condiciones institucionales muy diversas. Aun así, son frecuentes los intercambios entre las voces provenientes del campo académico y aquellas que conforman los documentos de los planes sociales que buscan combatir el desempleo y mejorar la "calidad" de la fuerza de trabajo. Así, el "Manual de Formación” en Orientación Profesional que publicó en el año 2006 el Ministerio de Trabajo y Empleo de la Nación es un texto práctico, destinado a capacitar al personal de las Instituciones de Formación Profesional que son agentes co-ejecutoras del Programa de Calidad del Empleo. A pesar de ello, está habitado por voces - contemporáneas e históricas - que se inscriben en el campo científico. Por su parte, los artículos académicos, si bien no suelen hacer alusión directa al rol que la orientación desempeña en el marco de las políticas públicas, incluyen múltiples referencias relativas al mundo del trabajo y de la producción. Sin dejar de reconocer la distancia que los separa, el discurso de la política social y el discurso de la expertise "psi" convergen - como mostraremos en la subsección siguiente - en pensar la orientación como una tecnología que, en sus múltiples áreas de actuación, busca optimizar el ingreso y la actuación de los individuos en el mundo del trabajo, así como asistirlos en la gestión de las múltiples situaciones de "transición” y "cambio" que, a lo largo de sus vidas, deberán experimentar.

Por el contrario, el análisis de los discursos correspondientes a nuestro "dominio de memoria"”, muestra que, entre 1920 y 1955, la preocupación por el empleo, si bien preponderante, no alcanzaba a explicar el sentido que entonces se atribuía a la orientación, y, en todo caso, se planteaba en el marco de otra red conceptual, en donde los temas de la "empleabilidad" y su reverso, la "inempleabilidad" no eran desconocidos, aunque se articularan con significantes diversos a los actuales. ${ }^{19}$

17 Esta sección del corpus, correspondiente al dominio de memoria, se constituyó a partir de las siguientes fuentes, correspondientes al período 1920-1955: las memorias del Congreso del Trabajo (1923), los Anales de la I Convención de Médicos de la Industria (1944), las Memorias de la II Conferencia para el Bienestar del Lisiado (1946), el Segundo Plan Quinquenal (1952), las publicaciones del Instituto de Psicotécnica y de Orientación Profesional dependiente del Ministerio de Justicia e Instrucción de la Nación y del Instituto de Psicología Experimental de la Universidad de Cuyo, manuales y tratados de psicotécnica, orientación profesional y medicina del trabajo y una serie diversa de artículos publicados en las revistas La Semana Médica, Jornada Médica, Humanidades, Clínica del Trabajo, Seguridad e Higiene Industrial, Anales de Biotipología, Eugenesia y Medicina Social y Medicina del Deporte y del Trabajo.

18 Nos referimos al corpus constituido a partir de las fuentes detalladas en la nota anterior.

19 A pesar de que la empleabilidad es un término de moda, una suerte de buzzword que se utiliza con frecuencia, no se trata de una invención del presente. Para la historia del concepto vid. GAUTIÉ, Jêrome. "De l'invention du chomage a sadeconstruction", Genese, n. 46, p. 60-76. En el ámbito argentino: GRONDONA, Ana. Tradición y traducción: un estudio de las formas contemporáneas del gobierno de las poblaciones desempleadas en la Argentina. Tesis de Doctorado en Ciencias Sociales. En: http://www.centrocultural. coop/uploads/tesisanaluciagrondona.pdf 


\section{II.1. La orientación y la cuestión de la empleabilidad}

En la actualidad, la reflexión y la práctica de la orientación están sobredeterminadas por el componente relativo al mercado de trabajo y a la configuración de las subjetividades adecuadas a su funcionamiento. Forma parte de la más extensa familia de las tecnologías "psi" que procuran asistir, acompañar, guiar, aconsejar a los individuos en las decisiones y acciones que configuran la vida laboral/profesional. En el caso de las actividades de orientación que se desarrollan en el marco del Programa de Calidad del Empleo y Formación Profesional del MTEySS, la actividad sobre la que recae la asistencia es la búsqueda de empleo y el desarrollo de estrategias personales de inserción en el mercado laboral.

Lo que se hace es asistir al individuo en toma de decisiones que refieren a su desempeño en cuanto fuerza de trabajo; se procura optimizar ese proceso mediante la reunión, organización y puesta a disposición de información relativa tanto al mercado de trabajo (en el sector específico de actividad de que se trate) como al trabajador mismo.

Desde la perspectiva de las autoridades (estatales), la orientación forma parte de la batería de instrumentos que junto a otros (la formación permanente, la certificación de competencias etc.) apuntan a mejorar la empleabilidad de los individuos, es decir, en términos del propio programa, a aumentar las oportunidades o chances de conseguir y mantener un empleo. La asistencia técnica que se ofrece reviste modalidades divergentes según los destinatarios sean "egresados" de algún curso de formación o bien personas que procuran insertarse por primera vez en el mercado laboral, presenten dificultades particulares para hacerlo o necesiten "reconvertir" su perfil profesional. En el primer caso (orientación para la búsqueda del empleo) la asistencia consiste en brindar herramientas que faciliten la confección y actualización de un CV, realizar entrevistas laborales exitosas, completar solicitudes de trabajo etc. En el segundo caso, la ayuda no concierne a la forma en que se busca empleo, sino a las estrategias (personales) de inserción en el mercado. Para que esas estrategias sean eficaces, el servicio de orientación (talleres, entrevistas etc.) procura evaluar las competencias y capacidades de los individuos a la luz de las posibilidades y restricciones del contexto productivo. ${ }^{20}$

En cambio, en la reflexión que tiene lugar en el campo académico, el propósito de la orientación aparece desagregado de acuerdo a la demanda del consultante, que, a diferencia de lo que ocurre con los programas sociales, no está presupuesta de antemano. Puede consistir en la elección de una profesión, una carrera, o bien en la gestión de un cambio. Es que la desaparición de la idea del empleo de por vida, la corrosión de la noción de carrera, la precarización laboral y el aumento del desempleo (entre otros fenómenos que la sociología del trabajo se ha ocupado exhaustivamente de describir) han impactado sobre esta clase de práctica, determinando la expansión de su campo de aplicación. Así, en la actualidad, junto a la clásica orientación para el trabajo aparecen otros "tipos específicos" de intervención, como la "orientación educativa" - dedicada a la inserción en los estudios y a mejorar el rendimiento académico - y la "orientación para la carrera”, entendida esta última como una suerte de asistencia para la realización de diferentes proyectos a lo largo

20 MTEySS. Orientación Profesional. Manual de Formación. Programa Calidad del Empleo y Formación Profesional. Disponible en: http://www.trabajo.gob.ar/downloads/capacitacion/calidad_programa.pdf, p. 84 y $85,2006$. 
de la vida. ${ }^{21}$ En todo caso, a diferencia de los discursos provenientes del campo de la política social, en la reflexión "psi” el acento está colocado más sobre la cuestión de la "elección" que de la "búsqueda". Como explica Rascovan"22 la "orientación" es una intervención tendiente a facilitar el proceso de elección de objetivos vocacionales. El énfasis está puesto en la idea de elección, pero los posibles "objetos" que dicha práctica considera provienen o del mundo del trabajo o del mundo de los estudios.

En los textos académicos, por otra parte, no hay alusión explícita a la empleabilidad. Esto no quiere decir, no obstante, que el "tema" de las condiciones para el empleo esté ausente. Esto es así, porque, aun articulada bajo la semántica de la "elección" y la "autonomía", la orientación continúa teniendo como horizonte de referencia la inserción en el mercado de trabajo y la obtención de un empleo. Aún en el marco de la "estrategia clínica", que es encuadre dominante en las reflexiones del campo, aquello que motoriza la acción de los psicólogos son los problemas que suscita en los individuos "su futuro como estudiantes y productores en el sistema económico de la sociedad a la que pertenecen". ${ }^{23}$

Por otra parte, la orientación se efectiviza, también en ambos casos, en un conjunto de acciones cuya eficacia depende de la "calidad" tanto de la información de la que se dispone, como de aquella que se procura producir en el marco de la relación "orientador-orientado", así como del "uso" que el segundo haga ella. Esa información refiere, por una parte, a una serie de dimensiones de carácter "social" o, por lo menos, supra-individual: la oferta y la demanda del mercado de trabajo (circunscripto localmente), la oferta de servicios educativos, las competencias requeridas para el desempeño de las distintas profesiones y ocupaciones. Y, por otra parte, concierne a toda una serie de aspectos de carácter estrictamente subjetivo: las “competencias", la biografía laboral y, en las intervenciones clínicas, a las potencialidades y deseos de los individuos.

En el ámbito del Programa de Calidad del Empleo y Formación Profesional del MTEySS, resulta explícito que la eficiencia del servicio de orientación se hace depender de la disponibilidad real de información acerca del mercado laboral y de las oportunidades de formación. Pero también en los encuadres clínicos el "suministro de información", relacionado tanto con lo "externo" - datos relativos a las carreras profesionales y a los roles ocupacionales del mundo adulto - como con lo "interno" - motivaciones personales, prejuicios etc. - se percibe como una instancia necesaria del proceso de orientación.

Una inquietud semejante inspiraba, como veremos en la sub-sección siguiente, asimismo, la reflexión de los expertos en la década del '20.

\section{II.2. La orientación frente a los desafíos de formar la fuerza de trabajo y aumentar su productividad}

También entre 1920 y 1955 la reflexión y las prácticas de la orientación estuvieron motivadas por toda una serie de preocupaciones concernientes al trabajo. Básicamente, los procesos de industrialización sustitutiva generados por las Guerras

21 MÜLLER, Marina. "Subjetividad y orientación vocacional profesional”. Orientación y Sociedad, La Plata, n. 4, p. 1-11, 2003.

22 RASCOVAN, Sergio. "Lo vocacional: una revisión crítica". Revista Brasileira de Orientacao Proffisional, v. 5, n. 2, p. 1-10, 2004.

23 BOHOSLAVSKY, Rodolfo. Orientación Vocacional. La Estrategia clínica. Buenos Aires: Nueva Visión, 1984, p. 14. 
Mundiales y la crisis económica de 1930, así como la progresiva conformación de un mercado interno, hicieron que esas inquietudes coagularan en torno a tres grandes ejes: la formación de una mano de obra idónea para atender los requerimientos de la industria, el aumento del rendimiento en el trabajo y la lucha contra el desempleo.

Si bien el significante empleabilidad no aparece en el corpus de documentos que integran nuestro "dominio de memoria" 24 , durante la primera mitad del siglo XX tuvo lugar una intensa reflexión en torno a uno de los nudos que articula la semántica de la empleabilidad, esto es, la cuestión de las "capacidades para el empleo". Contra las lecturas que piensan la responsabilización de los individuos respecto de su condición de empleo como un rasgo característico del liberalismo o el neoliberalismo ${ }^{25}$, se trata de un tema recurrente en la historia de la política social, con al menos un siglo de historia. ${ }^{26}$

En la actualidad, gracias a la incidencia del neoliberalismo, estamos acostumbrados a pensar en la formación profesional como una responsabilidad individual. Sin que la apelación a la actuación individual y familiar, estuviera excluida, entre 1920 y 1955, se entendía, en cambio, que la configuración de cuerpos aptos para el trabajo era, en gran medida, una responsabilidad del Estado.

Esa forma de pensar explica el rápido eco que el proyecto de Jesinghaus encontró entre las autoridades estatales. Aunque en la década del '30 (en el contexto de la crisis económica y política) las acciones en materia de orientación profesional provinieron del campo privado, el protagonismo estatal se recuperaría en la década del '40, alentado por el proceso de industrialización sustitutiva, la difusión de ideas intervencionistas y dirigistas y, finalmente, los objetivos de la política económica peronista: profundizar el proceso de acumulación de capital industrial por sustitución de importaciones y ampliar el mercado interno mediante el estímulo de la producción industrial local.

Es preciso destacar, en esta dirección, que la constitución de servicios "públicos" de orientación profesional había sido alentada en 1948 por la OIT, bajo dos modalidades: la asistencia prestada a adolescentes para elegir una profesión (orientación profesional en sentido estricto) y los "consejos sobre el trabajo", entendiéndose por estos la asistencia prestada a los adultos. ${ }^{27}$

Durante los gobiernos peronistas el Estado asumió un rol guía, organizador y regulador del ciclo de la producción, la distribución y el consumo. De conformidad con el objetivo, formulado en el Segundo Plan Quinquenal (1952) de lograr la independencia económica, se trató de satisfacer los requerimientos de mano de obra calificada provenientes de la industria, desarrollándose una activa política de enseñanza técnica.

Desde 1944 existía la Dirección de Enseñanza, Aprendizaje y Orientación Profesional. La acción de ese organismo, que, a partir de 1948 pasó a llamarse "Comisión Nacional de Aprendizaje y Orientación Profesional”, iba dirigida una población de jóvenes de entre 14 y 18 años. La Comisión controlaba el desempeño de una serie de servicios de aprendizaje industrial, que se prestaban en los propios establecimientos industriales o en escuelas creadas ad hoc. En el marco de dicho

24 Nos referimos al corpus constituido por los documentos enumerados en la nota n. 17.

25 FRADE, Carlos. "Gobernar a los otros y gobernarse a sí mismo según la razón política liberal”. Revista Española de Investigaciones sociológicas, n. 119, p. 35-64, 2007.

26 Cf. GRONDONA, Ana. Tradición y... op. cit.

27 ORGANIZACIÓN INTERNACIONAL DEL TRABAJO. Orientación Profesional. Trigésima Segunda Reunión. Informe IX. Ginebra: OIT, 1948, p. 34. 
sistema, en 1948 se creó un Instituto de Psicotécnica y Orientación Profesional, cuya función consistía en practicar exámenes psicotécnicos para los alumnos de las escuelas técnicas, de manera de aconsejarles la profesión más adecuada a sus aptitudes. Para ello, la Comisión contaba con un laboratorio central en la ciudad de Buenos Aires y laboratorios subsidiarios en el resto del país. Los métodos que se utilizaban eran aquellos experimentados por el Instituto de Orientación Profesional del Museo Social, que participó en su organización. En sí, la acción de la Comisión Nacional de Aprendizaje y Orientación Profesional contribuyó a solucionar, aún con carácter parcial y transitorio, el problema de la demanda de mano de obra calificada ${ }^{28}$, aunque los resultados de esa política recién se advertirían con nitidez durante las décadas del '60 y del '70, en la disponibilidad de una mano de obra altamente capacitada, formada durante el gobierno peronista. ${ }^{29}$

Para los cultores de la psicotécnica, la orientación y selección profesionales podía dar una respuesta a la "urgencia" que las estrategias de formación - cuyos resultados estaban diferidos en el tiempo - no conseguían satisfacer. Como argumentara Kaplan ${ }^{30}$ el ritmo de crecimiento de la industria había generado la necesidad de utilizar mano de obra proveniente de las regiones agrícolo-ganaderas o de sectores sin especialización previa. Si bien este problema intentaba ser revertido mediante la educación, los frutos del sistema tardarían años en aparecer. Pero entretanto, la única solución era acortar el tiempo del aprendizaje mediante la orientación y la selección profesional, asignando la mano de obra a los puestos para los que presentase aptitudes más destacadas. En este sentido, algunas experiencias de "selección", realizadas por Kaplan desde el ámbito privado (el Instituto de Orientación Profesional del Museo Social Argentino, en el Instituto de Psicotécnica y Racionalización dependiente del Instituto Argentino de Seguridad y algunas grandes empresas, que contaban con gabinetes propios) parecen haber arrojado resultados positivos. Así, por ejemplo, los departamentos de supervisión de la Compañía Argentina de Electricidad, la Fábrica Argentina de Alpargatas y los Talleres Metalúrgicos San Martín llegaron a la conclusión que la correlación entre el "pronóstico" emergente de los test y el "rendimiento" de los obreros seleccionados arribaba al 90\%31 pero se trata, claro está, de datos relativos a prácticas de "selección" y no de "orientación" profesional.

Mientras en el presente la problematización relativa a la formación de la fuerza de trabajo está regida por la semántica de las competencias (las cuales se entienden, en general, tanto en términos de destrezas como de atributos personales referidos a lo cognitivo y lo moral) en aquellos años, en cambio, la idoneidad para el trabajo venía definida por la posesión de las aptitudes, es decir, de disposiciones naturales de carácter innato ${ }^{32}$, requeridas para el desempeño de una labor específica. Más allá de la omnipresencia de dicha noción en el campo de la medicina y la psicología, la misma era objeto de interpretaciones diversas y contradictorias.

La corriente biotipológica entendía a las aptitudes desde un punto de vista esencialista. Cortada sobre el modelo de la medicina constitucionalista, consideraba que las disposiciones y debilidades hereditarias configuraban perfiles definidos

28 WIÑAR, David. Poder Político y Educación. El peronismo y la Comisión Nacional de Aprendizaje y Orientación Profesional. Buenos Aires: Instituto Torcuato di Tella, 1970.

29 WEINBERG, Daniel. La enseñanza técnica industrial en la Argentina1936-1966. Buenos Aires: Instituto Torcuato di Tella, 1967.

30 KAPLAN, Juan. "Selección y orientación profesionales". Medicina del Deporte y del Trabajo, Buenos Aires, n. 67, p. $1.766,1948$.

31 FINGERMANN, Gregorio. Fundamentos de Psicotécnica. Buenos Aires: El Ateneo, 1954, p. 40.

32 FINGERMANN, Gregorio. Fundamentos... op. cit., p. 172. 
de individuos o "biotipos". Así, en una obra de D. Boccia encontramos reproducida una de las ideas que organizan el pensamiento de N. Pende esto es, que existen "individuos nada o poco aptitudinales, que serán aptos solamente para peones" mientras que otros que son "poliaptitudinales". 33

También la psicología diferencial - en la que se fundaba la psicotécnica - tendía a establecer las desigualdades existentes entre los hombres en función de las aptitudes que cada uno poseía. Pero, a diferencia de la biotipología, no las esencializaba ni adscribía a esa clase de constataciones (científicas), juicios de valor. Los expertos que se desempeñaban en el Instituto de Orientación Profesional, consideraban - con E. Clapàrede - que el concepto de aptitud era "amoral", esto es, que estaba desprovisto de toda valorización ética. Para esta mirada, la aptitud era la "capacidad de realización" 34 de un cierto trabajo, es decir, designaba algo del orden del "hacer" y no del "ser".

Tal como fuera problematizada entre 1920 y 1955, la orientación no sólo estaba dirigida a la formación de la mano de obra requerida por la industria. Significaba en sí misma un factor de racionalización del trabajo. La conexión entre la orientación y el paradigma productivista ${ }^{35}$, que impregnó a las sociedades capitalistas con posterioridad a la Primera Guerra Mundial, estaba inscripta en su propia definición. En la significación que se le atribuía hasta bien entrado el siglo XX la orientación procuraba que los sujetos se dedicasen al tipo de trabajo en el que, con el menor esfuerzo pudieran obtener el mayor rendimiento, provecho y satisfacción. ${ }^{36}$

El descubrimiento "psi" de la "variabilidad" de los individuos había tenido un impacto decisivo en el campo de la producción y la economía. Como explicaba Kaplan37, la "compleja subdivisión del trabajo" que imponía la industrialización demandaba la investigación de las aptitudes específicas de cada individuo, porque se entendía que el rendimiento estaba en relación directa con los "valores cualitativos", con las "propias cualidades" de cada obrero. ${ }^{38}$ Si bien el movimiento psicotécnico y, asimismo, la escuela biotipológica, fueron muy críticas con el taylorismo en virtud del desprecio que el mismo importaba respecto del "factor humano", ambas corrientes admitían ampliamente la consigna "the right man on the right place". Todas las miradas concluían en que la asignación de cada hombre a la profesión que le correspondía de acuerdo a sus aptitudes físicas y mentales, contribuiría a aumentar la cantidad y calidad del trabajo ${ }^{39}$, a conseguir el mayor rendimiento con el mínimo gasto de energía ${ }^{40}$ y a acrecentar el rendimiento del capital humano. Pero, además de esta virtud "potenciadora", la orientación también podía funcionar cautelarmente, como medio para prevenir el desempleo.

33 BOCCIA, Donato. Tratado de Medicina del Trabajo. T.I. Buenos Aires: El Ateneo, 1947, p. 264.

34 FINGERMANN, Gregorio. Fundamentos... op. cit., p. 56.

35 Al finalizar la Primera Guerra Mundial el "productivismo" se convirtió en un común tanto para el management industrial europeo como para los movimientos tecnocráticos y pro-tayloristas de los Estados Unidos. Dicho paradigma estaba alimentado por una triple utopía: la eliminación de la crisis económica y social, la expansión de la productividad a través de la ciencia y el re-encantamiento de la tecnología (RABINBACH, Aaron. The human motor. Berkeley: UCP, 1992, p. 272).

36 MIRA y LÓPEZ, Emilio. Manual de Orientación Profesional. Buenos Aires: Kapeluz, 1947, p. 1.

37 KAPLAN, Juan. "Selección y...", op. cit., p. 1752.

38 YANKILEVICH, León. "La reeducación profesional de los accidentados del trabajo". Anales de Biotipología, eugenesia y medicina social, n. 90, p. 41, 1940.

39 SAGARNA, Antonio y JESINGHAUS, Carlos. "Proyecto de creación de un 'Instituto Central de Orientación Profesional'. Congreso del Trabajo. Santa Fe: Imprenta de la Provincia de Santa Fe, p. 334.

40 BOCCIA, Donato. "Constitución y Orientación Profesional". Anales de Biotipología, eugenesia y medicina social, n. 35, p. 10, 1935. 


\section{II.3. La orientación profesional como estrategia de lucha contra el desempleo}

Señalamos que, en el presente, la orientación se entiende como una estrategia destinada a optimizar las chances de que los individuos desempleados o con dificultades para conseguir un empleo, se inserten en el mercado de trabajo. Tal propósito aparece explícitamente articulado en el programa de formación profesional impulsado por el MTEySS pero resulta también considerado en los casos en los que el proceso de orientación acompaña - como leemos en los discursos expertos - la transición del empleo al desempleo. Así, la orientación desempeña un papel en el marco de las estrategias contemporáneas de gobierno del desempleo que buscan atacar el problema (individual) de la inempleabilidad.

En las reflexiones que acompañaron la instalación de los primeros gabinetes psicotécnicos en Argentina, convivían, en cambio, tanto la asunción de que el desempleo era un problema social, ligado a los desequilibrios y vaivenes que caracterizaban al mercado de trabajo, como una responsabilidad de los "individuos". En consonancia con esa explicación, la orientación se presentaba como una tecnología que permitía combatir ambos órdenes de causas (sociales e individuales), desempeñando, a la vez, una función "negativa" o "profiláctica” y otra "positiva”.

Por una parte, funcionaba como un factor profiláctico frente al peligro del desempleo porque se consideraba que la "ineptitud" era una causa legítima de despido. ${ }^{41}$ Por otra parte, uno de los objetivos que inspiró la instalación del Instituto de Psicotécnica y Orientación Profesional consistía en contribuir al "equilibrio" del mercado de trabajo. La particularidad del enfoque psicotécnico venía dada porque las estrategias a las que apelaba para abordar las fluctuaciones del mercado de trabajo, aunque se nutrían de datos socio-económicos, no eran económicas. De lo que se trataba era de modelar las decisiones individuales de los jóvenes a partir del conocimiento de un triple orden de factores: la vocación y las aptitudes, el presupuesto familiar, y el estado de las profesiones.

En este sentido, el proyecto de creación de dicho Instituto traducía la confianza en que, por medio de la centralización de los datos estadísticos relativos al grado de ocupación en cada gremio iba a ser posible una "repartición adecuada sobre las distintas profesiones, de acuerdo con las necesidades probables, resultando de este modo un mayor equilibrio entre la demanda y oferta en cada gremio". ${ }^{42}$ Sin embargo, ese optimismo fue rápidamente defraudado. En las Guías de Estudios Superiores publicadas por el Instituto de Psicotécnica y Orientación Profesional, las autoridades se lamentaban de la ausencia de cifras y narraban los denodados esfuerzos realizados para aproximarse con los datos disponibles a algo así como un "diagnóstico" del estado de cada gremio que permitiera conocer el porvenir de los universitarios. El "mal" a evitar era la superproducción de profesionales de una determinada especialidad. Frente a ese peligro, la utopía que motorizaba la acción de los orientadores consistía en una gran maniobra de ingeniería social: Jesinghaus, Fingermann y otros soñaban con disponer de estadísticas que permitie-

41 JESINGHAUS, Carlos. "Sobre la creación del Instituto Central de Orientación Profesional”. Humanidades, VIII, p. 397, 1923.

42 SAGARNA y JESINGHAUS, "Proyecto de creación..." op. cit., p. 335. INSTITUTO DE PSICOTÉCNICA Y ORIENTACIÓN PROFESIONAL. Guía de Estudios Superiores en la República Argentina. II Edición. Ministerio de Justicia e Instrucción Pública. Buenos Aires: Talleres Gráficos de la Penitenciería Nacional, 1928, p. 15. 
ran pronosticar "el número aproximadamente exacto de los profesionales nuevos, que realmente se han de necesitar cada año". ${ }^{43}$

Además de dirigirse a la población de “jóvenes”, la orientación profesional desempeñó un papel importante en los programas que - entre las décadas del ' 30 y del ' 40 - se idearon para gobernar a poblaciones que, si bien no se juzgaban como "inempleables" presentaba dificultades para la inserción en el mercado de trabajo. Así, se distinguía entre una "orientación del enfermo", dirigida a los cardíacos, incapacitados, etc. y otra destinada a aquellos que, habiendo fracasado en una profesión, debían buscar una nueva ocupación para ganarse la vida.

En el primer caso, la orientación permitía "restituir" a la sociedad un cuerpo que, aún en condiciones de inferioridad por la reducción de sus capacidades para el trabajo ${ }^{44}$, era todavía un elemento productivo, evitándose de esta manera que se convirtiera en una carga para la familia y el erario público. En los dos supuestos, se juzgaba que mediante la identificación de habilidades y aptitudes residuales u desconocidas, la psicotécnica podía reencauzar a los incapacitados y los "fracasados", poniéndolos en "buena vía mediante un reajuste profesional”. 45

Muchas eran, así, las expectativas que médicos, psicólogos y autoridades estatales depositaban sobre la orientación. Además de los motivos vinculados al empleo, otro de los propósitos que le atribuían consistía, como veremos en la subsección siguiente, en contribuir a la prevención de los accidentes de trabajo.

\section{II.4. La orientación como estrategia para la prevención de los accidentes y enfermedades de trabajo}

Durante la primera mitad del siglo XX se pensaba que la orientación profesional coadyuvaba al cuidado de la salud de los trabajadores porque de esa manera se podía evitar que los jóvenes eligiesen una carrera para la cual sus cuerpos no estaban preparados. Asimismo, se entendía que la orientación contribuía a reducir indirectamente la "accidentabilidad individual" 46 al disminuir el tiempo del aprendizaje y la adaptabilidad profesional. Ya en junio de 1929, en su 12va. Sesión la OIT había incluido a la psicotécnica como medio para prevenir los accidentes de trabajo. ${ }^{47}$

La conexión entre la orientación y la salud laboral fue particularmente explorada por los médicos que comulgaban con las ideas de la biotipología. D. Boccia ${ }^{48}$ sos- $^{-}$ tenía, por ejemplo, que el conocimiento de las predisposiciones y debilidades constitucionales a través de los test, permitiría evitar o disminuir las intoxicaciones, los accidentes y las degeneraciones. De manera más general, el Primer Congreso Argentino de Medicina del Trabajo, realizado en 1948, declaró que contribuían a la profilaxis de los accidentes y enfermedades del trabajo, facilitaban la rehabilitación de los inválidos, mejoraban el rendimiento y acortaban los períodos de aprendizaje.

43 INSTITUTO DE PSICOTÉCNICA Y ORIENTACIÓN PROFESIONAL. Guía de Estudios Superiores en la República Argentina. II Edición. Ministerio de Justicia e Instrucción Pública. Buenos Aires: Talleres Gráficos de la Penitenciería Nacional, 1928, p. 15.

44 FINGERMANN, Gregorio. “La orientación profesional del inválido”. En AAVV: Segunda Conferencia para el Bienestar del Lisiado. Buenos Aires: Asociación de Ayuda y Orientación al inválido, 1946, p. 291.

45 WEBER, Luis y ESCUDERO, César. "El problema médico social de los inválidos y mutilados". En: Anales de Biotipología, eugenesia y medicina social, n. 86, p. 14, 1940.

46 KAPLAN, Juan. “Experiencias y resultados en psicotécnica industrial”. Jornada Médica, v. V, n. 52, p. 390, 1951.

47 KAPLAN, Juan. "Ponencia”. En AAVV: Anales de la I Convención de Médicos de la Industria. Buenos Aires: Talleres Gráficos Index, 1944, p. 165.

48 BOCCIA, Donato. Medicina del Trabajo. Buenos Aires: Establecimiento Tipográfico de Guidi Buffarini, 1938, p. 71. 
La asociación entre la orientación y la prevención de los accidentes se vinculaba, asimismo, con uno de los primeros "rendimientos" (a la vez económico y sanitario) que la psicotécnica reportó tanto a la industria como al Estado. Corresponde recordar que el psiquiatra alemán $\mathrm{H}$. Münsterberg adquirió celebridad en los Estados Unidos por descubrir que las causas de los accidentes que provocaban, en la vía pública, los tranvías eléctricos, residía en la contratación de individuos que carecían de las aptitudes requeridas para desempeñar la profesión de "conductores". Mediante ese descubrimiento, Münsterberg no sólo efectuó un aporte a la salud pública sino que permitió que las compañías aseguradoras ahorrasen miles de dólares en el pago de indemnizaciones.

De la mano de la resonancia que había adquirido, durante el período de entreguerras, la teoría del "factor humano", médicos, ingenieros y psicólogos comenzaron a prestar más atención a las causas "subjetivas" de los accidentes y, con ellos, al problema de las "aptitudes" para el desempeño de diversas ocupaciones. Una asunción común en la literatura que los saberes del trabajo produjeron en las décadas del '30 y del '40 en la Argentina, era que el porcentaje más alto de infortunios se debía a las deficiencias e ineptitudes de los trabajadores. El éxito del que, por aquellos años, gozaban explicaciones que atribuían la causa de los accidentes a las características individuales de los trabajadores, hizo que la instancia de la "selección profesional" cobrase una inusitada relevancia tanto para la industria como para las autoridades de gobierno. En este sentido, Fingermann destaca que la evaluación con métodos psicotécnicos de más de 12.000 conductores de vehículos colectivos de la Corporación de Transportes de la Ciudad de Buenos Aires, había traído aparejada una disminución de los accidentes de tránsito. ${ }^{49}$ Asimismo, algunas empresas en las que se habían realizado, durante la década del '40, exámenes a sus conductores de vehículos (ESSO, Duperial, Alpargatas etc.) informaron sobre la coincidencia entre los resultados de esas pruebas y la accidentabilidad. ${ }^{50}$

Señalábamos antes que del tratamiento que la psicología diferencial y aplicada hacía de las aptitudes no se derivaba la idea de que existían hombres mejores o peores, sino sólo "más o menos aptos" para el desempeño de una determinada profesión. Sin embargo, esta clase de consideración "amoral" de las aptitudes que defendía Claparède y sus lectores en la Argentina - no impidió que el uso de los test fuera "contaminado" con la pretensión de identificar a "individuos accidentables”. Reproduciendo las conclusiones a las que había arribado, en 1926, el psicólogo alemán Karl Marbe, Kaplan aceptaba la idea de que existían individuos que tenían una propensión a sufrir un accidente. Se trataba de sujetos "con una estructura psíquica tal que les impide adoptar con rapidez, medidas de defensa ante los peligros, y por lo tanto son víctimas de accidentes". ${ }^{51}$

Ciertamente, el descubrimiento de individuos "accidentables" se procesaba mediante la práctica de la selección profesional, fundamentalmente, porque el objetivo perseguido era el ahorro de los costos que los accidentes reportaban a la industria. Sin embargo, la orientación no carecía de toda importancia, puesto que, además de la utilidad económica que la prevención significaba para el presupuesto de las empresas, otro de los fines ligados a ella era la conservación del capital humano de la nación, entendida esta última noción en un sentido "holístico". ${ }^{52}$

49 FINGERMANN, Gregorio. Fundamentos... op. cit., p. 40.

50 KAPLAN, Juan. "Experiencias y..." op. cit., p. 388.

51 KAPLAN, Juan. "Ponencia”. En AAVV: Anales de la I Convención de Médicos de la Industria. Buenos Aires: Talleres Gráficos Index, 1944, p. 169.

52 HAIDAR, Victoria. "Todo hombre en su justo lugar: la 'solución' biotipológica al conflicto entre productividad y salud (Argentina, 1930-1955). Salud Colectiva, Lanús, v. 7, n. 3, p. 317-332, 2011. 
Además de ello, la orientación aparecía como la tecnología adecuada para cauterizar toda una serie de anomalías laborales cuyas raíces eran psíquicas. Es que, como señalaba Horacio Rimoldi53, un psicólogo que se desempeñaba en la Universidad de Cuyo, en la atención de los diversos problemas que presentaba el medio industrial, se advertía un desplazamiento respecto de los temas vinculados directamente con la producción hacia aquellos que se referían a las características psíquicas de los obreros. Desde los años ' 40 la psicología comenzó a ingresar progresivamente en las fábricas. Una de las características de la política de salud laboral del peronismo consistió en la insistencia en torno a la importancia que revestía el factor "psi", tanto para la prevención de la fatiga y de patologías causadas por el trabajo industrial, como para el aumento de la productividad y la disminución de los conflictos en las fábricas. Se entendía que la adecuación de las aptitudes de los individuos a su trabajo contribuía a la profilaxis de las psicopatías industriales, suprimiendo el peligro de los numerosos efectos de contagio ligadas a ellas.

En esta sección hemos analizado los múltiples propósitos que, a lo largo de los años, se atribuyó a la orientación. En la sección siguiente nos ocuparemos de discernir los planos o dimensiones en los que la misma opera, así como su articulación con diversas racionalidades y discursos políticos y éticos.

\section{Entre el individuo y la sociedad}

En el año 1947 la editorial Kapeluz publica el Manual de Orientación Profesional de E. Mira y López, aquel psicólogo que escapó de la dictadura franquista exiliándose en Argentina y que tanta influencia tuvo en Brasil. En aquel texto, Mira y López introduce la clasificación que cifró gran parte de las interpretaciones y querellas que atraviesan las reflexiones sobre la orientación profesional, distinguiendo entre una práctica de orientación "individual" y otra "colectiva". Señalaba el autor que la primera "aspira a conseguir que cada sujeto se dedique al trabajo que mejor le cuadre" mientras que la segunda trata de conseguir que "la población trabajadora de un país se distribuya convenientemente en los diversos casilleros de oficios y carreras, de acuerdo con las conveniencias o requerimientos del plan económico-social vigente, para obtener el progreso nacional”. 54

Tan potente es la interpelación que suscita dicha taxonomía, que no sólo se convirtió en uno de los organizadores privilegiados para los historiadores de la profesión sino que, además, ha dejado sus marcas sobre una pluralidad de textos especializados que, al referirse a las prácticas actuales, no pueden dejar de hacer alusión a esas dos modalidades que tienden a "dicotomizar" la intervención orientadora. ${ }^{55}$ Con el correr de los años, esa oposición, que Mira y López jamás consideró irreconciliable, fue objeto de múltiples re-significaciones. En la década del '60, Luis $0 \mathrm{jer}^{56}$ la expresó en términos directamente ideológicos, diferenciando una tendencia "humanista", que prioriza los valores humanos y otra "utilitaria", que atiende más al bien de la sociedad y al rendimiento material que a la realización de aquellos valores.

53 RIMOLDI, Horacio. “Adecuación al trabajo”. Publicaciones del Instituto de Psicología Experimental, v. 1, n. 1, p. 8,1943 .

54 MIRA y LÓPEZ, Emilio. Manual de... op. cit., p. 8.

55 MÜLLER, Marina. "Subjetividad y..." op. cit., p. 9.

56 OJER, Luis. Orientación Profesional. Buenos Aires: Kapeluz, 1965, p. 215. 
Unos años después, Boholavsky emplazaría la mentada oposición en un terreno a la vez metodológico, teórico y político, distinguiendo entre una modalidad de orientación "actuarial" y otra "clínica". Más allá de las diversas interpretaciones, creemos que la diferenciación entre una orientación colectiva y otra individual constituye un excelente punto de partida para problematizarlas modalidades bajo las cuales dicha tecnología de gobierno se articuló, a lo largo del tiempo, con diversos saberes expertos, racionalidades políticas y discursos éticos.

\section{III.1. La "orientación" y la construcción de un proyecto profesional}

La estrategia "clínica" es la forma de encuadre que caracteriza a la orientación profesional en el presente. Si bien las primeras experiencias de ese estilo comenzaron a desarrollarse hacia los años '6o en el seno del Departamento de Orientación Vocacional de la Universidad de Buenos Aires, la misma sería formalizada por A. Boholavsky en la década del '70. En una obra que es un clásico de la disciplina, el autor estableció la diferencia entre una modalidad de orientación "actuarial" y otra "clínica", introduciendo un corte a la vez epistemológico y político entre el tipo de intervenciones de carácter "predictivo", fundadas en los desarrollos de la psicología diferencial, la psicometría y posteriormente, el análisis factorial, y las intervenciones inspiradas en la perspectiva psicoanalítica.

Ambas formas de encuadre parten de concepciones distintas acerca del sujeto, la relación que éste establece con el orientador y el objetivo de la propia práctica de orientación. Asimismo, piensan las aptitudes de manera divergente y recurren a diversas técnicas para conocerlas. La orientación actuarial supone que cada carrera y profesión requiere de aptitudes específicas, las cuales se consideran mensurables, definibles a priori y más o menos estables a lo largo de la vida. Para conocerlas se utilizan los test. Una vez conocidas las aptitudes del consultante, el psicólogo está en condiciones de proferir un "consejo" acerca de la profesión que más se ajusta a las posibilidades y gustos del individuo, el cual resume "lo que le conviene hacer”. En esta modalidad, el psicólogo se considera capaz de pronosticar, sobre la base del conocimiento de las aptitudes, la performance esperada del sujeto.

La clínica supone, en cambio, un enfoque individualizador y particularizante de la conducta humana. En ella, el rol del psicólogo es mucho más modesto porque la elección de una profesión se considera como una decisión personal y responsable del consultante. De allí que, en lugar de aconsejar, esclarece e informa. Asimismo, lejos de pensar que existen "aptitudes" para ciertas "profesiones", se considera que las carreras y profesiones requieren potencialidades que no son específicas, no pueden ser definidas a priori ni medidas. El instrumento adecuado para el conocimiento del "yo" no es el test sino la entrevista.57

Desarrollando algunos de los motivos característicos de dicha perspectiva, en la actualidad se subraya que la orientación no sólo parte de la demanda de un individuo, sino que promueve el "activo protagonismo de los consultantes"..$^{8} \mathrm{La}$ misma se concibe como un proceso psico-social de "acompañamiento" o "guía" para la elección de una profesión y la posterior inserción en el mercado laboral, que privilegia la escucha y promueve la autonomía y cuyo horizonte está dado por el desarrollo de una identidad ocupacional y profesional.

57 BOHOSLAVSKY, Rodolfo. Orientación... op. cit., p. 15-16.

58 MÜLLER, Marina. "Subjetividad y..." op. cit., p. 7. 
Al igual que la "clínica”, también las acciones que, en el marco del Programa de Formación para el Empleo procuran asistir a los individuos en la búsqueda de empleo y la definición de estrategias de inserción en el mercado de trabajo, se inscriben en la gran familia de orientación individual. Ninguna de esas dos prácticas "orientadoras" asume, strictu sensu, una modalidad clínica, aunque en algunos casos se prevé la utilización de la entrevista personal. Ahora, si bien el enfoque de tal clase de iniciativas no es en sí mismo particularizador, la orientación aparece como un instrumento dedicado a combatir un problema cuya explicación y solución se definen en términos individuales, es decir, como una cuestión de grados de empleabilidad/inempleabilidad. Asimismo, la reflexión acerca de la orientación que emerge del Manual de Formación de orientadores, está articulada, al igual que la modalidad clínica, en términos de una semántica de "autonomía", la "elección", y la "decisión responsable".

Más allá de las distancias que separan el pensamiento sobre la orientación profesional al interior del campo académico y de la política social, a los fines de este trabajo nos interesa resaltar cuatro aspectos.

Primero, que la acción de orientación se despliega desde un punto de vista “individual”, en el sentido de que tiende a optimizar, a volver más eficaz, el momento - todavía revestido de un aurea casi sacra - de la elección. Aun en aquellos planteos que tienden a deconstruir la noción de identidad vocacional/ocupacional, la orientación se define como el "acompañamiento en un determinado período de transición a construir una decisión”. 59

Segundo, que independientemente del "contexto" en que se desarrolle la orientación - una institución de formación profesional co-ejecutora de un programa social del MTEySS, la consulta privada, una escuela etc. - en todos los casos, el consultante está lejos de pensarse como una ficha suelta: se lo representa emplazado en una comunidad (la familia, la escuela, los beneficiarios de planes sociales). Esta última operación resulta estratégica para obtener la información que constituye, de alguna manera, el "combustible" del proceso en su conjunto. Pero ni la familia, ni el barrio, ni la escuela ni el colectivo de beneficiarios se piensan como interlocutores, co-partícipes o socios en el proceso de decisión.

Tercero, quién demanda la orientación aparece articulado en los discursos como un ser activo o que resulta "activado" en el proceso mismo de orientación. De lo que se trata - aún en el marco de los planes sociales - es de promover el desarrollo de la "capacidad de optar"60, la "realización de un hacer"61, de tomar decisiones atinentes a la formación o a la inserción en el mercado de trabajo.

Cuarto, el consultante - ora un joven estudiante de clase media o el beneficiario de un plan social - se concibe como una suerte de "proyectista" de sí mismo, como un arquitecto de su propia vida profesional. Lo que se espera de los "orientados" es que, a partir del conocimiento de sí mismos y de la realidad laboral que los circunda, elaboren un "proyecto personal de inserción social" ${ }^{62}$, identifiquen y construyan un "proyecto profesional" o un "proyecto ocupacional"63; valorándose, ambos, en términos de "proyectos de empleabilidad".

Para interpretar adecuadamente esta última característica, pero, en términos más generales, la afinidad entre estas formas de "orientación individual” y la

59 RASCOVAN, Sergio, “Lo vocacional..." op. cit., p. 8.

60 MTEySS, Orientación... op. cit., p. 54.

61 RASCOVAN, Sergio, "Lo vocacional..." op. cit,. p. 9.

62 MÜLLER, Marina, "Subjetividad y..." op. cit., p. 3.

63 MTEySS, Orientación... op. cit., p. 10. 
racionalidad política neoliberal, conviene recurrir a la analogía entre este "proyectista" de sí mismo y otras figuras a las que diversos autores han echado mano para hablar de las formas de subjetividad que activa el neoliberalismo: "empresario de sí mismo" ${ }^{64}$, homo prudens. ${ }^{65} \mathrm{Al}$ igual que el individuo que maximiza su performance a partir del cálculo de las inversiones y gastos en su capital humano, o de aquel que ha conseguido transformar el cálculo de riesgo en un hábito, el consultanteproyectista es, fundamentalmente, un sujeto reflexivo que está aplicado a la empresa de construir su propio profesional/ocupacional. La reflexividad involucra, en este contexto, tanto la identificación, esclarecimiento y "asunción" de las propias potencialidades y debilidades como su compulsa con los requerimientos del mercado de trabajo. El "proyecto" profesional/ocupacional es un proceso "dinámico y abierto" que se extiende - al igual que la formación - a lo largo de toda la vida. Es un opus que el individuo proyecta (imagina, concibe), ejecuta, timonea y a la vez evalúa. Sensible a requerimientos cambiantes y simultáneos, se espera que tenga la capacidad de ajustarlo y re-planificarlo cuántas veces sea necesario.

Como el empresario de sí mismo y el homo prudens, el consultante-proyectista está constreñido a efectuar toda una serie de elecciones, pero su decisión, en este caso, está revestida de un particular dramatismo, porque involucra una cierta cuota de incertidumbre que no está depositada en el exterior (la suerte del mercado bursátil, los efectos no queridos de un producto genéticamente modificado) sino en lo más profundo de sí. Ahora, mientras los cálculos de quién administra su propio capital humano y gestiona diligentemente los riesgos que atraviesan, en todo momento, la biografía personal y familiar, se despliegan por los carriles de la racionalidad (lo cual no excluye el repertorio de afecciones y sentimientos ansiedad, codicia, temor - ligados a la valorización del capital y a la conciencia del riesgo) la actividad de proyección que se espera que el consultante (debidamente asistido) realice, incluye una dosis de fantasía.

Así, en la actualidad, los rasgos que asume la orientación profesional están modelados, tanto por la clínica psicoanalítica como por la racionalidad política neoliberal. Ambas perspectivas - el saber "psi" y el arte de gobierno neoliberal - convergen en priorizar la "elección" y la "responsabilidad individual”, así como en invertir el papel que, tradicionalmente, la psicotécnica atribuyó al orientador y al orientado. Mientras en el pasado los psicólogos funcionaban de manera casi oracular, profiriendo el "consejo" que debía dirigir la elección, en la contemporaneidad se limitan a guiar la elección, lo que cuaja a la perfección con el papel esclarecedor e informador que, como vimos, Boholavsky les atribuía en los años '70.

Como veremos en la sub-sección siguiente, entre 1920 y 1955 la orientación profesional fue racionalizada desde perspectivas muy distintas a la clínica, conjugándose, asimismo, con discursos políticos y éticos que asumían un punto de vista social o nacional.

\section{III.2. La "orientación” y el bienestar de la nación}

Entre 1920 y 1955 la orientación "psicotécnica” funcionó como una estrategia dirigida a acoplar la formación y la ocupación de una serie de poblaciones (jóvenes, incapacitados etc.) a varios objetivos colectivos: limitar el conflicto de

64 Cf. FOUCAULT, Michel. Nacimiento de la Biopolítica. Buenos Aires: Fondo de Cultura Económica, 2007.

65 Cf. O’MALLEY, Pat. Riesgo, neoliberalismo y justicia penal. Buenos Aires: Ad-Hoc, 2006. 
clases, gobernar el desempleo (administrando adecuadamente los vaivenes del mercado de trabajo), promover el desarrollo de la industria nacional o aumentar la productividad del trabajo. Se tratara de formar una mano de obra idónea, evitar las crisis por superproducción de profesionales, fomentar la re-colocación de los incapacitados o evitar la proliferación de "resentidos", la orientación involucraba, en todos los casos el punto de vista - si bien no exclusivo - de la "sociedad" y/o de la "nación". Formulados tanto desde el campo experto y de las instituciones públicas, esos propósitos se combinaron, según las épocas, con el desarrollo de políticas laborales, educativas y económicas en las que el Estado desempeñó algún rol "activo" vis à vis el mercado y la sociedad civil.

En lo que atañe a la cuestión social y la cuestión nacional, durante los gobiernos radicales (1916-1930), el Estado asumió un rol "conciliador" y "armonizador" entre capital y trabajo manifestando, asimismo, posiciones (tibiamente) favorables a la intervención en la economía y el desarrollo de una política nacionalista enfocada a lograr una mayor independencia económica. ${ }^{66}$ Así, entre la instalación del Instituto de Orientación Profesional (1925) y su desmantelamiento en 1931, las acciones de orientación se alinearon con las intenciones de los gobiernos radicales de acompañar el desarrollo de la industrialización sustitutiva y el incremento de la profesionalización, así como de arbitrar en los conflictos sociales, contribuyendo a la pacificación social. El sesgo conciliador y, más generalmente, el programa "ético" del radicalismo - con todo su repertorio de valores: respeto a la Constitución Nacional, democracia, honradez administrativa, austeridad, armonía social, tolerancia etc. - se nutrían de las ideas krausistas. ${ }^{67}$ Pues bien, en el contexto de este programa de "armonización" entre los diversos grupos sociales y de "moralización" de la sociedad que el radicalismo procuró llevar a cabo, la orientación profesional (tal como la concebía Jesinghaus) desempeñaba un rol estratégico. Esto es así, porque las propuestas psicotécnicas de este psicólogo alemán estaban influidas, ellas mismas, por el pensamiento krausista. ${ }^{68}$ Jesinghaus y sus discípulos rechazaban las concepciones materialistas del trabajo y proponían reemplazar esta noción por la de "profesión" que adquiría una significación espiritual. En consonancia con estas ideas, atribuían a la orientación toda una serie de funciones "ético-sociales" referentes al mantenimiento de la paz entre las clases, la disminución de la criminalidad y, en fin, la generación de orden social mediante la "espiritualización" de la vida profesional. En palabras del propio autor:

\footnotetext{
El restablecimiento de un lazo personal entre cada individuo y el trabajo profesional adecuado a sus dones, conducirá a la formación de una nueva 'conciencia profesional' y quitará al trabajo el carácter de una ocupación meramente económica con el fin exclusivo de la ganancia, agregando un motivo esencialmente humano, de sumo valor ético. La orientación profesional contribuirá de este modo a sustituir el materialismo económico por una concepción más elevada de nuestra vida y de nuestro trabajo que reconoce la supremacía de los valores personales y espirituales. ${ }^{69}$
}

66 MARCAIDA, Elena; RODRíGUEZ, Alejandra \& SCALTRITTI, Mabel. "Los cambios en el Estado y la sociedad. Argentina (1880-1930)”. En: AAVV: Historia Argentina contemporánea. Buenos Aires: Dialektik, 2008, p. 90.

67 MARCAIDA, Elena (et. al.) "Los cambios..." op. cit.

68 ROSSI, Lucía. “Los socialistas...” op. cit. y ROSSI, Lucía. “Instituciones de psicología aplicada según períodos políticos y cambios demográficos en Argentina. Vestigios de profesionalización”. En: L. ROSSI y colaboradores. Psicología: su inscripción como profesión. Buenos Aires: Eudeba, 2001, p. 141-161.

69 JESINGHAUS, Carlos. “La función social de la orientación profesional”. Revista de Criminología, Psiquiatría y Medicina Legal, n. 121, p. 75, 1934. 
Con la progresiva intensificación, durante la década del '20, de las ideas nacionalistas y fascistas, el sesgo "patriótico" que se imprimía a la orientación profesional de los jóvenes se fue acentuando. Así, en un texto escrito por un ex juez de menores, que expresaba la preocupación por el destino profesional de los estudiantes, se insistía sobre la "inutilidad" de los "doctores" y la necesidad apremiante de formar "técnicos" y hombres prácticos. ${ }^{70} \mathrm{Y}$ ante la amenaza de su cierre, Jesinghaus defendía la utilidad del Instituto de Orientación Profesión en términos nacionalistas: "En estos tiempos difíciles la orientación profesional se pone al servicio de toda la nación unida solidaria e inexorablemente en una sola comunidad de trabajo". ${ }^{71}$

Frente a la ausencia de indicadores macroeconómicos relativos a los mercados de trabajo de las distintas profesiones y, más aun, de datos que permitan conocer el impacto que tuvieron los servicios prestados por el Instituto de Psicotécnica y Orientación Profesional sobre los mismos, no estamos en condiciones de ponderar el grado en que todos aquellos objetivos "sociales" se realizaron, si es que lo hicieron en alguna medida. Ello se dificulta, asimismo, por la ausencia de información relativa a la porción de la población universitaria y trabajadora que fuera efectivamente "orientada". Ciertamente, en las memorias anuales que elaboraba dicha institución están consignados la cantidad de "pedidos individuales" de orientación atendidos, el número de consultas detalladas realizadas (provenientes de todas las provincias) y la cantidad de interesados que pasaron por el Instituto para solicitar la "Guía de Estudios Superiores".

Teniendo en cuenta esos datos, particularmente el "aumento constante del movimiento de consultas" Jesinghaus llegaba a la conclusión, en 1931, que la institución satisfacía "una necesidad realmente sentida en la población", tanto de las familias como de los educadores. Así, para las autoridades, el hecho de que en algunas instituciones educativas hubieran comenzado a ensayar las propuestas divulgadas por el Instituto, era una prueba por demás de elocuente de que el problema de la orientación había despertado el interés espontáneo de los educadores. ${ }^{72}$ Pero resultaría inadecuado evaluar la "recepción" que las prácticas desarrolladas desde ese ámbito tuvieron entre las poblaciones de estudiantes, educadores y trabajadores, considerando solamente las "voces" de los especialistas; más aún cuando sus opiniones tendían a justificar (frente al Estado) la necesidad de financiar sus propias actividades profesionales. Por otra parte, tampoco es posible afirmar que, por ejemplo, los "2.089" interesados que en 1930 pasaron por el Instituto a retirar la "Guía de Estudios Superiores"73 fuera efectivamente "orientados".74

En la década del '30, como ya mencionamos, los esfuerzos relativos a la orientación provinieron del campo privado. Pero eso no impidió que su problematización quedara asociada a motivos anti-liberales. Esto último es claro en la reflexión que se desarrolló en el ámbito de la biotipología, dada la afinidad entre esta última y las ideas corporativistas que inspiraron el golpe de Estado con el cual el general José F. Uriburu derrocó, en 1930, el gobierno constitucional de Hipólito Irigoyen. La biotipología soñaba con colocar "cada hombre en su justo lugar, con

70 PUCIARELLI, Carlos. Orientación profesional de la juventud argentina. Marcos Paz: Colonia Hogar Ricardo Gutierrez, 1928, p. 27.

71 JESINGHAUS, Carlos. "Instituto de Psicotécnica y Orientación Profesional. Memoria del año 1930", Semana Médica, n. 26, p. 1800, 1931.

72 JESINGHAUS, Carlos. La cooperación de la escuela primaria en la orientación profesional. Buenos Aires: Instituto de Psicotécnica y Orientación Profesional, 1927, p. 12.

73 JESINGHAUS, Carlos. “Instituto...” op. cit., p. 1797.

74 Ello requeriría adentrarnos en las peripecias de los efectos que tal clase de prácticas tuvieron sobre los individuos y grupos, lo cual excede el propósito de este artículo. 
sus capacidades constitucionales fisicopsíquicas en la estructura de la colectividad y de la Nación". ${ }^{75}$ Mientras la práctica de la orientación inspirada por la psicología experimental, diferencial y aplicada respetaba la libertad individual y atribuía un lugar destacado a la vocación, la solución biotipológica asumía una forma autoritaria. El acoplamiento entre los puestos de trabajo y los cuerpos no podía depender ni de la "espontaneidad" de los deseos ni de las leyes sociales de la imitación, sino que debía regirse por la palabra de la ciencia, si quería evitarse una acumulación en la colectividad de una «masa amorfa» de ineptos, desilusionados y descontentos, que produce poco y representa una carga para el presupuesto económico y energético de la Nación. ${ }^{76}$ Así, para el director de la oficina de orientación y selección profesional del Instituto de Psicotécnica, correspondía al Estado velar por que cada niño de hoy fuera un "hombre de provecho" que contribuyera con su acción material, intelectual o espiritual al engrandecimiento de la patria común".77

Promediando la década del '40, en un campo político e intelectual en el que, frente a todo un repertorio de problemas (qué hacer con los enfermos cardíacos, con los incapacitados, con las mujeres etc.), se imaginaban y experimentaban diversas formas de gobierno social, la cuestión de la "formación profesional" no fue la excepción. En esos años, asistimos a la configuración de una trama discursiva caracterizada por la exaltación del punto de vista (holista) de la sociedad y de la nación y el rebajamiento de la problemática vocacional. Alimentada y permanentemente reformulada durante los gobiernos peronistas, la misma estaba constituida por enunciados como los siguientes:

Desde el punto de vista social, la salud [... ] la capacidad intelectual y el rendimiento profesional no sólo condicionan la existencia de los individuos sino que actuaban sobre todos aquellos que estaban ligados a él en el marco del contrato social, sea que se vinculen en la profesión o en la colectividad social o política. ${ }^{78}$

La organización nacional del aprendizaje profesional requiere el esfuerzo material, intelectual y espiritual de todo el país. No es el triunfo de una idea o concepción política lo que se persigue [... ] sino el afianzamiento de la prosperidad económica de la nación y la defensa de su acervo cultural, moral y espiritual. ${ }^{79}$

Todo trabajo profesional debe ser concebido por quien lo ejerce, en servicio de la totalidad y 'el no involucrar el factor conveniencia social en el concepto global de aptitud profesional es colocar la pieza humana frente a una producción sin rendimiento o a la espera de la necesidad de su actividad como simple consumidor. ${ }^{80}$

Para los médicos formados en la biotipología, como D. Boccia, cuyo curso de medicina del trabajo recibió el premio Juan D. Perón, era claro que los derechos individuales debían ceder frente a los fines públicos, y que la vocación podía ser sacrificada en miras de las "aptitudes". Pero una idea semejante puede leerse, también en el Manual de Orientación Profesional, publicado en el país ese mismo año, por un exiliado de la dictadura franquista:

75 BOCCIA, Donato. Tratado de... op.cit., p.257.

76 BOCCIA, Donato. Medicina del... op.cit., p.149.

77 OLIVES, Ángel. "La orientación profesional en nuestro país ¿cómo encararla? Anales de Biotipología, Eugenesia y Medicina Social, n. 90, p. 18, 1940.

78 POCHAT, Roberto. "La psicotécnica y la orientación profesional en la industria”, Seguridad e Higiene Industrial, n. 1, p. 6, 1944.

79 UCHA, Alberto. Orientación profesional y aprendizaje. Santa Fe: Imprenta de la Universidad Nacional del Litoral, 1945.

80 MONDRÍA, Julio. "La orientación profesional del obrero en las industrias, un factor importante en su rendimiento”, Clínica del Trabajo, n. 22, 23, 24, p. 17, 1946. 
Hay quienes confunden la democracia con la anarquía, y creen que en materia de orientación profesional [...] los derechos individuales han de ser respetados ilimitadamente. [... Cuando alguien, escudándose en su posición política, económica o cultural, intenta acometer una labor técnica profesional para la que [...] no se halla suficientemente capacitado, el orientador $[\ldots]$ debe oponerse a tal intento. ${ }^{81}$

Asimismo, en el Prólogo que Alfredo Calcagno escribió para la publicación en la Argentina del libro de Mira y López, reclamaba a los poderes públicos la constitución de un "servicio nacional de orientación profesional científicamente organizado"; anticipándose a la Convención de la OIT, que un año después sugeriría lo mismo. "Hay que preparar especialmente a los jóvenes para que cada uno vaya a ocupar el lugar de su mayor eficiencia en tal fábrica, en tal oficina [... ] participando dignamente en la obra del progreso social y de mejoramiento colectivo". ${ }^{82}$

Justamente, eso fue lo que trató de hacer el peronismo, al interpelar a cada ciudadano como un "trabajador" que - protegido por una serie de derechos sociales - estaba obligado a contribuir patrióticamente al proyecto de lograr la soberanía económica nacional y, con ello, la grandeza del país. En el marco del régimen de gobierno "ecléctico" ${ }^{83}$, que fue el peronismo, caracterizado por una combinación de elementos populistas, nacionalistas, católico-sociales, neo-corporativistas etc. el objetivo de formar una mano de obra calificada y, con él, la orientación profesional, asumió un papel relevante. Sus autoridades sanitarias insistieron en sacarla de los laboratorios y llevarla a las fábricas, integrándola con las actividades de aprendizaje y formación profesional.

Así, promediando la década del '40, tanto desde posiciones autoritarias como desde aquellas democráticas y respetuosas del Estado de derecho, se entendía que, tratándose de la cuestión de la vida profesional y de la economía nacional, las libertades individuales debían ceder frente al interés de la sociedad y de la nación. Sin embargo, dicho consenso tenía sus fisuras. B. Bosio, un médico heterodoxo, alzó su voz para criticar el carácter anti-liberal de las propuestas que los biotipólogos habían efectuado en el Primer Congreso de Medicina y Sociología del Trabajo, realizado en ese año. ${ }^{84}$

Si bien las propuestas de los biotipólogos resultaban alarmantes, corresponde señalar que, en la Argentina, la modalidad "prescriptiva" de la orientación nunca se practicó en forma generalizada. Sólo tenemos constancia de que, a lo largo de la década del '40, algunas poblaciones circunscriptas de trabajadores, aprendices y aspirantes, vinculadas con instituciones y servicios públicos - así, los empleados de la Caja Nacional de Ahorro Postal, los aspirantes de la Escuela de Reclutamiento del Ministerio de Marina - fueron sujetas, efectivamente a prácticas de orientación, desarrolladas por el Instituto de Orientación Profesional del Museo Social Argentino. En el ámbito privado, las prácticas de orientación se realizaron en aquellas empresas que contaban con "escuelas de aprendices", tales como la Compañía Argentina de Electricidad. ${ }^{85}$

Una década después, en una tesis dedicada a discutir las causas psíquicas del ausentismo se criticaba la propuesta que la OIT había hecho en la Convención del

81 MIRA y LOPEZ, Emilio. Manual... op. cit., p. 54.

82 CALCAGNO, Alfredo. "Prólogo". En: MIRA y LOPEZ, Emilio. Manual... op. cit., p. LV.

83 BUCHRUCKER, Cristian. Nacionalismo y peronismo. Buenos Aires: Sudamericana, 1987, p. 301.

84 BOSIO, Bartolomé. "Breves consideraciones sobre los propósitos del Primer Congreso de Sociología y Medicina del Trabajo”, La Semana Médica, n. 49, p. 1337-1339, 1939.

85 KAPLAN, Juan. “Experiencias y...” op. cit., p. 389. 
año 1948, en relación a la organización de servicios públicos de orientación profesional. "Creemos que este criterio es peligroso. Se abandona mucho al individuo, se aleja demasiado de la personalidad del obrero para adentrarse con exceso en los requerimientos de la sociedad". ${ }^{86}$

Con independencia de estas "grietas", como veremos en la sub-sección siguiente, la impronta colectiva que la orientación asumió entre 1920 y 1955 no alcanzaba a bloquear toda expresión de la subjetividad y la libertad individual, cómo, a la inversa, tampoco la modalidad "clínica" se encuentra al margen, en el presente, de toda estrategia política.

\section{III.3. Circuitos: entre la ética y la política}

En la actualidad, la orientación profesional presupone y tiende a fortalecer y encauzar la capacidad de elección de un sujeto, contribuyendo, de esta manera, a incrementar su empleabilidad. Su reflexión resulta circunscripta a una semántica en la que predominan significantes afines a las estrategias neoliberales de gobierno: autonomía, elección, competitividad etc. Ahora bien, tanto en el discurso experto como en aquel de la política social, los "orientados" aparecen connotados como formando parte de unas comunidades delimitadas por vínculos de parentesco, de vecindad o de "riesgo". Particularmente, en la literatura "psi", lo social resulta significado en ocasiones en términos de "relaciones de interdependencia", entendidas como un factor constitutivo del sujeto y, en otras, como las "condiciones materiales de existencia" que "condicionan" [sic] la elección. ${ }^{87}$ Asimismo, toda una serie de datos "macro" o "supra-individuales" ingresan en el cálculo que inspira la búsqueda de un empleo o la elección de una profesión; básicamente, información relativa al mercado de trabajo.

Lo que está ausente en esas reflexiones es, no obstante, tanto el punto de vista de la "sociedad" como de la "nación". Así, la orientación se desarrolla al margen de la "sociedad" entendida como una totalidad formada por relaciones de solidaridad y de conflicto, atravesada por jerarquías y modalidades de exclusión, o de la "nación" definida en términos de un grupo humano asentado sobre un territorio que comparte una lengua, una cultura, unos mitos fundadores, un destino común etc. Se despliega, en cambio, en otras espacialidades: unas "comunidades" parciales (la escuela, la familia, el colectivo de beneficiarios de planes sociales), el "mercado de trabajo" y, asimismo, en el territorio moral de la "subjetividad".

Sin embargo, aún en ausencia de los registros "holistas" de la sociedad y la nación, esta clase de acciones están hilvanadas en una estrategia "macro" de gobierno. La orientación profesional apunta, como otras tecnologías, a configurar/ modelar/inducir una forma específica de la subjetividad. En esa dirección, forma parte de un cálculo o de una estrategia política más general: en tanto contribuye a la formación de sujetos "autónomos", "activos", "reflexivos", refuerza y racionaliza la "elección" (ocupacional/profesional), constituye uno de los resortes éticos de la forma específica de gubernamentalidad que es el neoliberalismo.

En este sentido, el incremento de la empleabilidad y el fortalecimiento de la autonomía, dos de los propósitos a los que tiende la orientación profesional, están alineados con el objetivo "macro" de aumentar la competitividad de la economía

86 KNOBEL, Mauricio. Etiología del ausentismo. Tesis de Doctorado. Facultad de Ciencias Médicas, 1952, p. 97. 87 RASCOVAN, Sergio, “Lo vocacional..." op. cit., p. 2. 
nacional. ${ }^{88}$ Como ha sido largamente argumentado, entre las características que distinguen al neoliberalismo, se encuentra la extensión del principio de la competencia y el modelo de la empresa a todos los ámbitos de la vida social ${ }^{89}$ y la asunción, por parte del Estado, de una forma "reflexiva" de gobierno. ${ }^{90}$ En lugar de intervenir directamente sobre los procesos sociales del mercado, la educación, la cultura etc. gobierna promoviendo la adopción por parte de los individuos y grupos de comportamientos competitivos.

A la inversa, entre 1920 y 1955, la orientación aparecía como una acción directamente encaminada a la realización de una serie de objetivos colectivos (la independencia económica, la paz social etc.). Pero también involucraba - bajo diversas modalidades - alguna elaboración de lo "subjetivo" y se asentaba sobre una semántica (entre psicológica y ético-política) que incluía la noción de vocación, el concepto de personalidad, una concepción espiritual de la profesión, y toda una serie de motivos humanistas. Así, la reflexión sobre la orientación profesional constituyó, en esos años, uno de los tópicos que - más allá de todos los cálculos de utilidad - atrajo y condensó los esfuerzos, inquietudes, proyectos y utopías de "moralización" del mundo del trabajo y de la producción, que compartieron - con todas las distancias existentes entre ellos - los gobiernos radicales y los psicólogos, los biotipólogos y las autoridades políticas e intelectuales del peronismo.

Las expectativas "éticas" que C. Jesinghaus y G. Fingermann depositaron sobre la orientación profesional estaban alimentadas por el discurso de la filosofía krausista el cual, como vimos, constituía, también uno de los insumos ideológicos del radicalismo. En consonancia con la impronta anti-positivista y materialista del krausismo, así como con su énfasis sobre la armonización entre la realización individual y las necesidades de la sociedad ${ }^{91}$, para dichos psicólogos estaba claro que la elección de la carrera era una cuestión eminentemente ética, en la que contaba tanto la satisfacción personal como la utilidad social. En esta dirección, Jesinghaus atribuía a la escuela la misión de mostrar a los estudiantes la diferencia entre el mero trabajo (cuyo único propósito era obtener dinero) y el "trabajo profesional", que proporciona no sólo sostén sino el "contenido de la vida". ${ }^{2}$ Desde las Guías de Estudios Superiores se insistía en denostar el "materialismo burdo" que, en algunos casos, regía la elección profesional, resaltándose la importancia de los motivos éticos.

La orientación se fundaba, así, en un "triple esclarecimiento" de carácter ético, técnico-económico y psicofísico. Si bien el individuo no se concebía, como en la actualidad, como un ser "activo", la primera operación de esclarecimiento convocaba un trabajo ético, del "yo" en relación a sí mismo. "Es necesario estudiarse a sí mismo para descubrir su verdadera vocación y no caer en errores respecto a sí mismo", explicaba Jesinghaus ${ }^{93}$ y desde el Instituto de Psicotécnica y Orientación se señalaba que el problema de la idoneidad para el desarrollo de una profesión dependía del "conocimiento de sí mismo" y de un "severo auto-examen".

Asimismo, esta reflexión atribuía a la vocación un peso, si bien no exclusivo, sí decisivo en la determinación de la carrera. Tal como surge de los textos que dicho Instituto producía, en la ponderación de los factores que incidían en la elección de una carrera, el estudiante debía dar prevalencia a la vocación.

88 MTEySS, Orientación Profesional... op. cit., p. 3.

89 Cf. FOUCAULT, Michel. Nacimiento de la Biopolítica. Buenos Aires: Fondo de Cultura Económica, 2007.

90 Cf. DEAN, Mitchell. Governmentality... op. cit.

91 BIAGINI, Hugo. "Precursores del Estado de Bienestar". En: H. BIAGINI (comp.). Orígenes de la democracia argentina. El trasfondo krausista. Buenos Aires: Legasa, 1989, p. 206-225.

92 JESINGHAUS, Carlos. La cooperación de la escuela primaria en la orientación profesional. Buenos Aires: Instituto de Psicotécnica y Orientación Profesional, 1927, p. 5.

93 JESINGHAUS, Carlos. La cooperación... op. cit., p. 5. 
En la tradición psicotécnica inaugurada por Jesinghaus, la subjetividad resultaba articulada bajo el concepto de personalidad. La inclinación de Fingermann, Kaplan y otros especialistas, hacia el uso de test ergológicos permite comprender que, para esta perspectiva, la orientación debía dar cuenta de la individualidad, mediante un meticuloso trabajo de "articulación” y “composición” de las diversas aptitudes.

Lo que importa, pues, es determinar la personalidad global del sujeto [...]. El test debe ser, por lo tanto, analítico y sintético a la vez. Una vez descompuesta la personalidad con los mismos fragmentos se debe reconstruir la personalidad, no a la manera de mosaico sino con el objeto de descubrir cuál es el resorte fundamental, cuál es el rasgo típico que lo determina dándole una fisonomía propia. ${ }^{94}$

Esta clase de mirada marca una distancia importante respecto del estudio analítico de las aptitudes. Asimismo, da cuenta de la afinidad entre esta forma de concepción integral de la personalidad, el uso de test ergológicos y el enraizamiento, en algunos círculos políticos e intelectuales de los años '20, de ideas krausistas. ${ }^{95}$

También para la biotipología la psicotécnica estaba conectada con la preocupación por moralizar el mundo del trabajo mediante la asignación de cada individuo al puesto que le correspondía de acuerdo a su biotipo. Asimismo, al igual que la orientación de inspiración "psi”, pero sobre los fundamentos de la medicina constitucionalística, los biotipólogos pensaban a los sujetos en términos de "individualidad" y "personalidad" y defendían la idea de la unidad fundamental del hombre. Esta visión integral de lo humano se explica porque la biotipología junto a otros saberes constituía una de las ramificaciones del holismo médico de entreguerras, que se caracterizaba por pensar el cuerpo de manera sistémica, enfatizar las conexiones entre las diversas dimensiones, propender a una mirada "sintética" e interdisciplinaria etc. Sin embargo, a diferencia de los psicólogos que compartían las ideas krausistas, los biotipólogos argentinos no fueron totalmente consecuentes con el "holismo" que defendían. Así, en los escritos de D. Boccia convivía la idea del ser humano como "personalidad" con la metáfora fisicalista del "motor humano". ${ }^{96}$ Asimismo, mientras los métodos que preconizaban Jesinghaus y Fingermann eran ergológicos, para estudiar la «individualidad» los biotipólogos procedían a descuartizar al ser humano en varias facetas para luego reconstituirlo, integrando y correlacionando los datos acumulados en la investigación de cada de ellas. Idéntico reduccionismo transpiraba la obsesión por la elaboración de «biotipos» que, por su carácter ideal, generaban tensiones con la idea de individualidad.

Durante los gobiernos peronistas las experiencias en materia de orientación siguieron el modelo de los test que venían aplicándose desde 1931 por el Instituto de Orientación Profesional del Museo Social, con lo que existe continuidad entre los exámenes practicados en el marco del gabinete psicotécnico de la Comisión de Enseñanza y Orientación Profesional y la evaluación de las aptitudes realizada por los psicólogos krausistas. También en el caso del peronismo, y más allá del objetivo de formar la mano de obra calificada que requería la industria, se advierte el proyecto de moralizar el mundo de la producción, contribuyendo a la "dignificación" del trabajo y a la armonía entre las clases sociales. Pero los fundamentos de este programa "ético" no deben buscarse en este caso en el krausismo, sino en la doctrina social de la Iglesia.

94 FINGERMANN, Gregorio. Fundamentos... op. cit., p.59.

95 Cf. ROSSI, Lucía. "Instituciones de..." op. cit.

96 Cf. HAIDAR, Victoria "Cada uno..." op. cit. 


\section{Conclusiones}

Emergente en la década del '20 del siglo pasado, la problematización sobre la orientación profesional asumió a lo largo del tiempo diversas significaciones, explicables en función de la acción de múltiples y heterogéneas condiciones, entre las que se cuentan. a) Condiciones de carácter epistémico, relativas a la forma cómo diversos saberes expertos hicieron pensable la orientación en el transcurso de los años. Así, la misma asumió una modalidad "psicotécnica", que fue racionalizada y se nutrió del conocimiento producido por la psicología experimental, la psicología diferencial, la psicología aplicada, la biotipología, y una modalidad "clínica", de inspiración psicoanalítica. b) Factores de orden técnico, vinculados con los cambios que sufrieron los instrumentos utilizados para conocer las "aptitudes", “competencias" y "potencialidades" (así: test analíticos, test ergológicos, entrevistas) y con las expectativas que los expertos depositaban sobre ellos (medición o esclarecimiento de las aptitudes, etc.). c) Cuestiones ligadas a problemas del "gobierno" de diversas poblaciones (jóvenes, incapacitados, desempleados). Tal como mostramos a lo largo del artículo, la orientación profesional es una tecnología lo suficientemente dúctil como para ser integrada en diversas estrategias políticas. Así, a lo largo de las décadas, se incluyó en los programas de armonización social y moralización de la vida profesional que encarnaron tanto los gobiernos radicales como los psicólogos krausistas; en las utopías corporativistas de los médicos de inspiración biotipológica; en el programa nacionalista, católico-social y neo-keynesiano del peronismo y, finalmente en el esquema de gobierno neoliberal que expresa el programa de formación profesional del MTEySS. d) Factores económico-sociales: tanto los expertos como las autoridades políticas atribuyeron a la orientación la función de atender a diversas "urgencias", derivadas de la rápida e improvisada industrialización, la carencia de mano de obra idónea, el aumento de la conflictividad social, el incremento del desempleo y la necesidad de atender a las demandas de competitividad provenientes del mercado global.

Lejos de estar sobredeterminada, como en la actualidad, por los problemas del mercado de trabajo, entre 1920 y 1955 la orientación se alineó hacia la realización de diversos fines, que venían definidos tanto desde el campo experto como desde el ámbito de la política: pacificación social, moralización de la vida profesional, prevención de los accidentes de trabajo, racionalización del trabajo, gobierno de las poblaciones incapacitadas. Pero el carácter polivalente que dicha tecnología asumió en sus orígenes no debe opacar la existencia de continuidades a lo largo del tiempo. También la cuestión de la "empleabilidad" (aunque la "palabra" no fuera utilizada) se articulaba, por entonces, en términos semejantes a los contemporáneos, es decir, como un problema de las capacidades para el empleo. Sin embargo, mientras en el presente (más allá de la acción "facilitadora" y "promotora" del Estado) la empleabilidad se concibe como una responsabilidad de los individuos, hasta la primera mitad del siglo XX era, a la vez, un asunto tanto de los individuos (cuya ineptitud era causa legítima de despido) como del Estado.

Así, bajo diversas formas, entre 1920 y 1955, la orientación se pensó como una tecnología que permitía organizar, mediante una intervención ad hoc, los desarrollos espontáneos que venían realizándose en el ámbito de la educación y del trabajo, de manera de acoplar la producción de profesionales, técnicos, obreros calificados etc. a los requerimientos de la "economía nacional" y/o del "mercado". Esta pretensión de "acoplamiento" y "armonización" entre los proyectos familiares/individuales y aquellos capitalistas/estatales, asumió una forma autoritaria 
en el pensamiento de los biotipólogos, y liberal en el resto de los casos. La orientación no era, solamente, una medida destinada a prestar un servicio al capital. Por el contrario, en el afán por "asignar" a los individuos a las ocupaciones que les correspondían según sus aptitudes, o bien "aconsejarlos" acerca de lo que les convenía hacer, anidaba, también, un proyecto político. Se trataba de contribuir a la producción del orden social "por-medio-de" la satisfacción en el trabajo, la disminución del desempleo y la moralización de la vida profesional.

En la actualidad, en cambio, las acciones de orientación profesional no están integradas en ningún master plan. De lo que se trata es de acompañar el proceso de elección de una carrera/ocupación y/o de guiar y facilitar la búsqueda laboral, poniendo a disposición del sujeto herramientas que faciliten, refuercen y optimicen el conocimiento de las propias competencias, capacidades, inclinaciones; las recapitulaciones y reflexiones relativas a la propia historia profesional y, asimismo, el conocimiento de las características del mercado de trabajo. El sesgo "pronosticador" que caracterizaba a la psicotécnica, y que se conecta con la voluntad (política) y la utopía tecnocrática de anticiparse a los desarrollos del mercado, está completamente ausente en las reflexiones del presente.

Esto no significa, no obstante, que la orientación esté desprovista de toda significación política. Como vimos, la última ratio del programa de formación profesional del MTEySS consiste en incrementar la competitividad de la economía nacional, un objetivo que es compartido (y reclamado) tanto desde el ámbito estatal como desde el ámbito del capital. De manera más sutil, en la medida en que la orientación contribuye a la configuración de los sujetos autónomos, responsables, activos, competentes etc. sobre los que se funda el arte de gobierno neoliberal, la misma asume una significación política.

Asimismo, a lo largo del artículo mostramos que, al contraponer "orientación colectiva" a la "orientación individual", o la modalidad psicotécnica a la modalidad clínica, se suele opacar el hecho de que, también entre 1920 y 1955, existió una cierta elaboración de lo "subjetivo". En la reflexión psicotécnica estamos lejos del individuo "activo" y responsable que construye su propio proyecto profesional/ocupacional pero, no obstante, el concepto de personalidad confería un sustento psicológico a la libertad, entendida como "ejercicio yoico de una voluntad autónoma". ${ }^{97}$

Más allá de la importancia de reconocer que la reflexión sobre la orientación está modulada por diversos énfasis, es preciso señalar que, en todos los casos, lo "individual" y lo "colectivo" aparecen, en alguna medida, entremezclados. Ello es así en virtud de la afinidad, característica del presente, entre la semántica "psi" y el neoliberalismo. Pero, asimismo, porque entre 1920 y 1955 la satisfacción de objetivos colectivos se alineaba con toda una serie de esfuerzos por moralizar la vida profesional, que atendían a la personalidad y a los componentes vocacionales.

Es preciso observar, por otra parte, que esa imbricación entre lo individual y lo social aparece replicada en la forma en que - de manera persistente - en el discurso psicológico, médico y, asimismo, de la política pública, la orientación se concibe como un proceso de encastre, de ajuste o adecuación entre distintas dimensiones o planos, algunos de los cuales quedan ubicados en el lugar de la interioridad (y, por lo tanto, de lo subjetivo, lo íntimo etc.) y otros en un lugar de exterioridad y exteriorización (y por lo tanto, de lo público, de que se pone en común etc.). En el lado de la interioridad aparece la vocación y toda su semántica. En el lado de la exterioridad, el mercado de trabajo y sus demandas pero, asimismo,

97 ROSSI, Lucía. “Instituciones...” op. cit., p. 146. 
otras dimensiones que siendo "del sujeto", constituyen manifestaciones, exteriorizaciones, objetualizaciones de sí mismo, como las aptitudes y, en el vocabulario contemporáneo las competencias.

Entre estas dos tendencias, la orientación se concibe con una tecnología "transaccional", que busca acercar y compatibilizar lo interno con lo externo, la vocación con la aptitud, la vocación con la demanda de empleo, los intereses (muchas veces antinómicos) del individuo y la sociedad. En la década del '40, J. Kaplan sostenía que poseer vocación para una actividad más la aptitud necesaria para realizarla equivalía al éxito, a la satisfacción propia y el beneficio de la sociedad, pero si se daba la vocación y no la aptitud, el resultado era el fracaso, el resentimiento y la liberación de un elemento antisocial. También en el presente el proyecto profesional se concibe como aquello que aúna "vocación", con la "demanda de empleo", "vocación” con las "competencias personales”. 